\title{
Incidence and predictors of coronary stent thrombosis: Evidence from an international collaborative meta-analysis including 30 studies, 221,066 patients, and 4276 thromboses
} \author{
Giacomo Frati ${ }^{\mathrm{t}}$, Giuseppe Biondi-Zoccai ${ }^{\mathrm{t}, *, 1}$ \\ ${ }^{a}$ Division of Cardiology, University of Turin, Turin, Italy \\ ${ }^{\mathrm{b}}$ Division of Cardiology, University of Tor Vergata, Rome, Italy \\ c Division of Cardiology, Uppsala Clinical Research Centre, Uppsala University, Uppsala, Sweden \\ d Division of Cardiology, Hospital Marques de Valdecilla, Santander, Spain \\ e Department of Cardiology, St Antonius Hospital, Nieuwegein, The Netherlands \\ ${ }^{\mathrm{f}}$ LeBauer Cardiovascular Research Foundation, Greensboro, NC, USA \\ ${ }^{\mathrm{g}}$ Division of Cardiology, La Tour Hospital, Meyrin, Switzerland \\ h Odense University Hospital, Odense, Denmark \\ i Division of Cardiology, Washington Hospital Center, Washington, DC, USA \\ jivision of Cardiology, Washington University School of Medicine, St. Louis, MO, USA \\ ${ }^{\mathrm{k}}$ Deutsches Herzzentrum, Technische Universitat, Munich, Germany \\ ${ }^{1}$ Columbia University Medical Center and the Cardiovascular Research Foundation, New York, NY, USA \\ ${ }^{\mathrm{m}}$ Division of Cardiology, IRCCS Multimedica, Sesto S. Giovanni, Italy \\ ${ }^{n}$ EMO GVM, Centro Cuore Columbus, Milan, Italy \\ ${ }^{\circ}$ Hôpital Cardiologique, Lille, France \\ p Division of Cardiology, Wake Forest University School of Medicine, Winston-Salem, NC, USA \\ ${ }^{q}$ Department of Cardiology, Careggi Hospital, Florence, Italy \\ ${ }^{\mathrm{r}}$ Jagiellonian University School of Medicine, Krakow, Poland \\ ${ }^{s}$ Division of Cardiology, University of Modena and Reggio Emilia, Modena, Italy \\ ${ }^{t}$ Department of Medico-Surgical Sciences and Biotechnologies, Sapienza University of Rome, Latina, Italy
}

Fabrizio D'Ascenzo ${ }^{\mathrm{a}, 1}$, Mario Bollati ${ }^{\mathrm{a}}$, Fabrizio Clementi ${ }^{\mathrm{b}}$, Davide Castagno ${ }^{\mathrm{a}}$, Bo Lagerqvist ${ }^{\mathrm{c}}$, Jose M. de la Torre Hernandez ${ }^{\text {d }}$, Juriën M. ten Berg ${ }^{\text {e }}$, Bruce R. Brodie ${ }^{\mathrm{f}}$, Philip Urban ${ }^{\mathrm{g}}$, Lisette Okkels Jensen ${ }^{\mathrm{h}}$, Gabriel Sardi i , Ron Waksman i , John M. Lasala ${ }^{\mathrm{j}}$, Stefanie Schulz ${ }^{\mathrm{k}}$, Gregg W. Stone ${ }^{\mathrm{l}}$, Flavio Airoldi ${ }^{\mathrm{m}}$, Antonio Colombo ${ }^{\mathrm{n}}$, Gilles Lemesle ${ }^{\mathrm{o}}$, Robert J. Applegate ${ }^{\mathrm{p}}$, Piergiovanni Buonamici ${ }^{\mathrm{q}}$, Ajay J. Kirtane ${ }^{1}$, Anetta Undas ${ }^{\mathrm{r}}$, Imad Sheiban ${ }^{\mathrm{a}}$, Fiorenzo Gaita ${ }^{\mathrm{a}}$, Giuseppe Sangiorgi ${ }^{\mathrm{b}}$, Maria Grazia Modena ${ }^{\mathrm{s}}$,

\section{A R T I C L E I N F O}

\section{Article history:}

Received 18 September 2011

Received in revised form 24 January 2012

Accepted 26 January 2012

Available online 22 February 2012

\section{Keywords:}

Coronary artery disease

Drug-eluting stent

Meta-analysis

Stent

Stent thrombosis

Systematic review

\begin{abstract}
A B S T R A C T
Background: Stent thrombosis remains among the most feared complications of percutaneous coronary intervention $(\mathrm{PCI})$ with stenting. However, data on its incidence and predictors are sparse and conflicting. We thus aimed to perform a collaborative systematic review on incidence and predictors of stent thrombosis. Methods: PubMed was systematically searched for eligible studies from the drug-eluting stent (DES) era $(1 / 2002-12 / 2010)$. Studies were selected if including $\geq 2000$ patients undergoing stenting or reporting on $\geq 25$ thromboses. Study features, patient characteristics, and incidence of stent thrombosis were abstracted and pooled, when appropriate, with random-effect methods (point estimate [95\% confidence intervals]), and consistency of predictors was formally appraised.

Results: A total of 30 studies were identified (221,066 patients, 4276 thromboses), with DES used in $87 \%$. After a median of 22 months, definite, probable, or possible stent thrombosis had occurred in $2.4 \%$ (2.0\%; $2.9 \%)$, with acute in $0.4 \%(0.2 \%$; $0.6 \%)$, subacute in $1.1 \%(1.0 \% ; 1.3 \%)$, late in $0.5 \%(0.4 \% ; 0.6 \%)$, and very late in $0.6 \%(0.4 \% ; 0.8 \%)$. Similar figures were computed for studies reporting only on DES. From a total of 47 candidate variables, definite/probable stent thrombosis was more commonly and consistently predicted by early antiplatelet therapy discontinuation, extent of coronary disease, and stent number/length, with acute
\end{abstract}

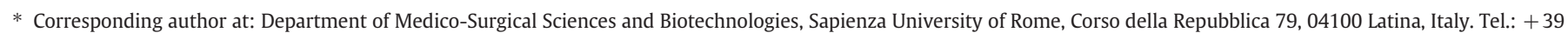
077317572 45, + 393408626 829(mobile); fax: + 3907731757254 .

E-mail address: gbiondizoccai@gmail.com (G. Biondi-Zoccai).

${ }^{1}$ Equally contributed to this work
} 
coronary syndrome at admission, diabetes, smoking status, and bifurcation/ostial disease also proving frequent predictors, but less consistently.

Conclusions: Despite numerous possible risk factors, the most common and consistent predictors of stent thrombosis are early antiplatelet therapy discontinuation, extent of coronary disease, and stent number/ length.

\section{Introduction}

Stent thrombosis is a catastrophic, although relatively uncommon, complication of percutaneous coronary intervention (PCI) [1,2]. Stent thrombosis can present as ST-elevation myocardial infarction or cardiogenic shock in up to $75 \%$ and $30 \%$ of cases, respectively, with case fatality reaching $18 \%$ during the index hospitalization and $25 \%$ at 1 year [2-8]. Furthermore, up to $39 \%$ of patients with stent thrombosis experience a recurrent myocardial infarction within the first month despite an initially successful repeat PCI [9-11]. These striking data were among the main reasons for international recommendations to prolong dual antiplatelet therapy to 12 months or even longer in those undergoing PCI with drug-eluting stents (DES), especially after acute coronary syndromes (ACS); for a more selective use of DES, and to develop more effective antithrombotic agents [12-15].

All physicians taking care of patients who receive coronary stents, including but not limited to interventional cardiologists, should be thoroughly knowledgeable of the risk of stent thrombosis, and of predisposing/protective features, which might drive decision-making before as well as after stenting. However, the evidence base on stent thrombosis in the current era is fraught with conflicting data on risk and predictors, which remain difficult to overcome without a systematic and collaborative approach. Stemming from previous similar endeavors from our research group, we aimed to perform an international collaborative systematic review and meta-analysis focusing on incidence and predictors of coronary stent thrombosis in the DES era.

\section{Methods}

This work was conducted in keeping with current guidelines, including the recent Preferred Reporting Items for Systematic reviews and Meta-Analyses (PRISMA) amendment to the Quality of Reporting of Meta-analyses (QUOROM) statement, as well as recommendations from The Cochrane Collaboration and Meta-analysis of Observational Studies in Epidemiology (MOOSE) [16-19]. The review was also registered online at its inception on metcardio.org to minimize duplicate efforts [16].

\subsection{Search strategy}

MEDLINE/PubMed was searched for pertinent articles published in English between January 2002 (when DES were first marketed worldwide) and December 2010 according to the following strategy, in keeping with established methods [20] and incorporating wild cards (identified by *): stent* AND thrombosis AND coronary AND english[lang] AND ("2002"[pdat] : "2010"[pdat]) NOT (review[pt] OR editorial[pt] OR letter[pt]). We did not search The Cochrane Collaboration CENTRAL database, as it only includes controlled clinical trials. In addition we avoided EMBASE and articles published in non-English languages as it is very unlikely that high quality observational studies with $\geq 2000$ patients undergoing stenting or $\geq 25$ stent thromboses were published in non-English journals not indexed in MEDLINE/PubMed. Nonetheless, all corresponding authors of shortlisted studies were systematically and repeatedly queried for additional quantitative details. Concomitantly, they were asked for additional pertinent studies on the topic, and offered coauthorship in the present work.

\subsection{Study selection}

Retrieved citations were first screened independently by two unblinded reviewers (GBZ, FDA) at the title and/or abstract level, with divergences resolved after consensus. If potentially pertinent, they were then appraised as complete reports according to the following explicit selection criteria, which were piloted over the first 5 cases. Inclusion criteria were (all had to be met for inclusion): (i) human studies, (ii) investigating patients undergoing PCI with stent, (iii) published between 2002 and 2010, (iv) including $\geq 2000$ patients undergoing stenting or $\geq 25$ stent thromboses (irrespective of the definition), and (v) reporting predictors of stent thrombosis obtained through multivariate analysis. Exclusion criteria were (any one alone was enough for exclusion): (i) non-human setting, (ii) duplicate reporting (in which case the manuscript reporting the largest sample of patients with stent thromboses was selected, or if equal, the study with the largest number of overall patients), or (iii) control group limited to patients with other kinds of coronary thromboses (i.e. de novo myocardial infarction).

We a priori chose to discard studies with $<2000$ patients and $<25$ stent thromboses as they were unlikely, given established assumptions of multivariable analysis methods, to provide valid and robust incidence and prognostic estimates [21].

\subsection{Data extraction}

The following data were independently abstracted by two unblinded reviewers (GBZ FDA) on pre-specified electronic forms, which were piloted over the first 5 cases, with divergences resolved after consensus. In particular, authors, journal, year of publication, location of the study group, baseline, angiographic and procedural features, stent thromboses (total number and distinguished as definite, definite or probable, and acute, subacute, late and very late according to the Academic Research Consortium [ARC] definitions), and multivariate predictors (estimator, point summary estimate of risk, 95\% confidence intervals) [22]. Specifically, ARC distinguished stent thrombosis as acute (0-24 h after stenting), subacute (2-30 days), late (31-365 days), or very late ( $>365$ days). Moreover, definite stent thrombosis was defined as angiographically or pathologically proven stent thrombosis. Probable stent thrombosis was defined as any unexplained death within the first 30 days after stenting or, irrespective of time after procedure, any myocardial infarction related to documented acute ischemia in the territory of the implanted stent without angiographic confirmation of stent thrombosis and in the absence of any other obvious cause. Possible stent thrombosis was defined as any unexplained death from 30 days after stenting until end of follow-up. Data from studies published before the adoption of ARC definitions were extracted and abstracted in keeping with the definition used in each individual study. Thus, angiographically proven thrombosis was considered equivalent to ARC definite thrombosis, and clinically adjudicated thrombosis was considered equivalent to ARC definite, probable or possible thrombosis. Nonetheless, all corresponding authors of included studies were systematically queried to confirm or disprove abstracted data. End-points of interest for the present review were the incidence of stent thrombosis at the different time points as well as multivariable predictors of stent thrombosis. Given the exploratory yet comprehensive scope of this collaborative review, no explicit primary end-point was specified.

\subsection{Internal validity and quality appraisal}

The quality of included studies was independently appraised by two unblinded reviewers (GBZ, FDA), on pre-specified electronic forms, which were piloted over the first 5 cases, with divergences resolved after consensus. Modifying the MOOSE item list in order to take into account the specific features of included studies [18], we separately abstracted and appraised study design, setting, data source, and statistical methods for multivariable analysis, as well as, in keeping with The Cochrane Collaboration approach, the risk of analytical, selection, adjudication, detection, and attrition bias (expressed as low, moderate, or high risk of bias, as well as incomplete reporting leading to inability to ascertain the underlying risk of bias).

\subsection{Data analysis and synthesis}

Continuous variables are reported as mean (standard deviation) or median (1st; 3rd quartile). Categorical variables are expressed as $\mathrm{n} / \mathrm{N}$ (\%). Statistical pooling for incidence estimates was performed according to a random-effect model with generic inverse-variance weighting, computing risk estimates with $95 \%$ confidence intervals, using RevMan 5 (The Cochrane Collaboration, The Nordic Cochrane Centre, Copenhagen, Denmark). Conversely, risk estimates were not pooled from individual studies as this approach would have not been feasible and valid given the high risk for publication bias). We instead adopted Ross et al.'s approach [23], and appraised the prevalence of studies in which a given predictor was proven significantly and independently associated with the outcome of interest. Small study bias was appraised by graphical inspection of funnel plots. Hypothesis testing for superiority was set at the two-tailed 0.05 level. Hypothesis testing for statistical homogeneity was set at the two-tailed 0.10 level and based on the Cochran Q test, with I2 values of $25 \%$, $50 \%$, and $75 \%$ representing, respectively, mild, moderate, and extensive statistical inconsistency. 


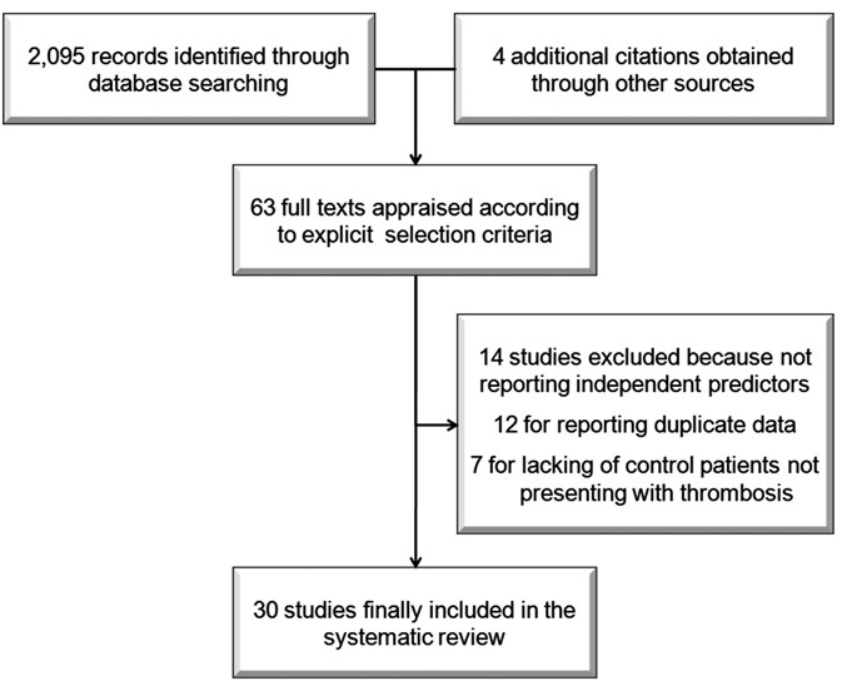

Fig. 1. Review profile.

\section{Results}

\subsection{Review profile and included studies}

From a total of 2095 initial citations, we thoroughly assessed for eligibility 63 complete reports, after discarding 15 studies enrolling between 1000 and 2000 patients. From the above 63, 14 citations were excluded because they did not report on independent predictors of stent thrombosis [24-37], 12 because of duplicate reporting [2,3848], and 7 because of focus on the early and long-term outlook of stent thrombosis in comparison to ST-elevation myocardial infarction [4-6,47-50]. Finally, 30 studies were included in the systematic review, including, 221,066 patients, and 4276 thromboses (Fig. 1, Online only Table 1, Online only Table 2 ) [3,7,51-78].

The most important features of these studies are summarized in Table 1. Briefly, their design was more frequently retrospective (63\%), with a multicenter setting in 63\%, and more than two thirds were conducted in North America or Europe. A median of 4790 patients and 93 stent thromboses were included, with a median follow-up of 22 months. Patients had a median age of 63 years, 25\% were women, 26\% reported diabetes mellitus, and 59\% presented at admission with an ACS (Table 2).

In order to identify independent predictors of stent thrombosis, several approaches to multivariable analysis were employed by the

Table 1

Key features of included studies.

\begin{tabular}{lc}
\hline Studies & $\mathrm{N}=30$ \\
\hline Study design & \\
$\quad$ Prospective cohort & $11(37 \%)$ \\
$\quad$ Retrospective cohort & $19(63 \%)$ \\
Data source & $1(3 \%)$ \\
$\quad$ Clinical database & $2009(2008 ; 2009)$ \\
$\quad$ Post-marketing database & \\
Year of publication & $11(37 \%)$ \\
Setting & $19(63 \%)$ \\
$\quad$ Single center & \\
$\quad$ Multicenter & $1(3 \%)$ \\
Location & $2(7 \%)$ \\
$\quad$ Worldwide & $10(33 \%)$ \\
Asia & $17(57 \%)$ \\
$\quad$ North America & $4790(2069 ; 7982)$ \\
Europe & $93(59 ; 145)$ \\
Patients undergoing percutaneous coronary stenting & $22(12 ; 36)$ \\
Patients with stent thrombosis & \\
Follow-up (months) & \\
\hline
\end{tabular}

Reported as median (1st; 3rd quartile) or $\mathrm{n} / \mathrm{N}$ (with studies as denominator).
Table 2

Key patient and procedural characteristics.

\begin{tabular}{ll}
\hline Studies & $\mathrm{N}=30$ \\
\hline Patients & $\mathrm{N}=221,066$ \\
Age (years) & $63(62 ; 65)$ \\
Male gender & $165.800(75 \%)$ \\
Diabetes & $57,035(26 \%)$ \\
Acute coronary syndrome at admission (including AMI, \%) & $130,650(59 \%)$ \\
AMI at admission & $44,213(20 \%)$ \\
Left ventricular ejection fraction at admission (\%) & $53(51 ; 56)$ \\
Multivessel disease & $81,352(37 \%)$ \\
Left anterior descending stenting & $95,942(43 \%)$ \\
Implanted device & \\
$\quad$ Bare-metal stent implantation only & $4(13 \%)$ \\
Drug-eluting stent implantation only & $15(50 \%)$ \\
Both bare-metal and drug-eluting stent implantation & $12(37 \%)$ \\
\hline
\end{tabular}

Reported as median (1st; 3rd quartile) or $\mathrm{n} / \mathrm{N}$ (with patients or studies as denominators, as appropriate); $\mathrm{AMI}=$ acute myocardial infarction.

authors of primary studies, but the most frequent was a stepwise process (43\%) with various entry criteria (Table 3). Appraisal of the internal validity and quality of included studies showed that most of them were at low risk for analytical, adjudication and attrition bias, whereas selection bias was clearly more present, as typical of retrospective cohort studies focusing on uncommon and ominous events. In addition, some incomplete reporting was evident, involving in particular adjudication and attrition details.

\subsection{Meta-analysis for the incidence of stent thrombosis}

Meta-analytic pooling by means of random-effect methods yielded a risk of definite, probable and possible stent thrombosis at a median of 22 months of $2.4 \%$ (2.0\%; $2.9 \%)$ with $1.5 \%$ (1.3\%; $1.8 \%)$ for definite thrombosis (Fig. 2). Acute $(<24 \mathrm{~h})$ stent thrombosis occurred in $0.4 \%(0.2 \%$; $0.6 \%)$, definite subacute thrombosis in $1.0 \%$ $(0.8 \% ; 1.2 \%)$, definite late in $0.4 \%(0.3 \% ; 0.5 \%)$, and definite very late in $0.5 \%(0.3 \% ; 0.7 \%)$.

Table 3

Internal validity of included studies.

\begin{tabular}{ll}
\hline Studies & $\mathrm{N}=30$ \\
\hline Multivariate analysis approach & \\
Bootstrap & $1(3 \%)$ \\
Conditional logistic regression & $5(17 \%)$ \\
Inclusion of all clinical and angiographic features & $9(33 \%)$ \\
Propensity score & $2(7 \%)$ \\
Stepwise selection & \\
p $<0.05$ entry criterion & $3(10 \%)$ \\
p $<0.10$ entry criterion & $7(23 \%)$ \\
p $<0.20$ entry criterion & $2(7 \%)$ \\
p $<0.25$ entry criterion & $1(3 \%)$ \\
Selection bias & \\
Low risk & $12(40 \%)$ \\
Moderate risk & $18(40 \%)$ \\
High or unclear risk & 0 \\
Attrition bias & \\
Low risk & $15(50 \%)$ \\
Moderate risk & $7(23 \%)$ \\
High risk & 0 \\
Unclear & $8(27 \%)$ \\
Adjudication bias & \\
Low risk & $21(70 \%)$ \\
Moderate risk & $6(20 \%)$ \\
High risk & 0 \\
Unclear risk & $3(10 \%)$ \\
Lnalytical bias & $18(60 \%)$ \\
Moderate risk & $12(40 \%)$ \\
High or unclear risk & 0 \\
\hline
\end{tabular}

Reported as n/N (with studies as denominator). 


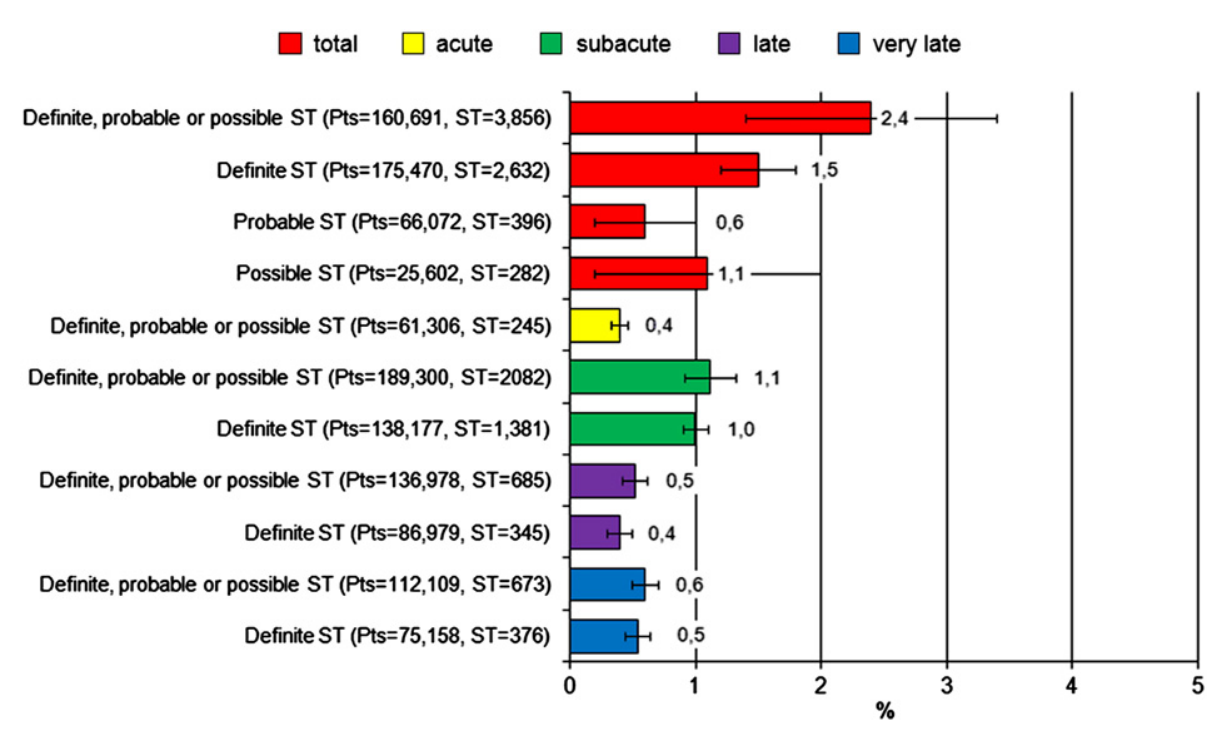

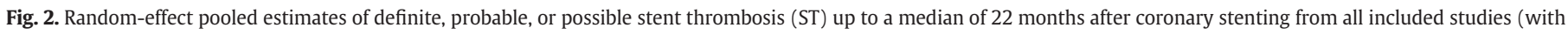
median drug-eluting stenting implantation rate of $95 \%$. Patients (Pts) included and overall stent thromboses are reported in brackets.

Among patients receiving only DES (Fig. 3), definite, probable or possible stent thrombosis occurred in $3.1 \%$ of patients, including definite stent thrombosis in $1.5 \%(1.3 \% ; 1.8 \%)$. The timing of definite stent thrombosis in such subset of studies was acute in $0.2 \%(0.1$; $0.2 \%)$, subacute in $0.8 \%(0.7 ; 0.9 \%)$, late in $0.4 \%(0.3 ; 0.5 \%)$, and very late in $0.4 \%(0.2 ; 0.6 \%)$. Graphical inspection of funnel plots did not disclose evidence of small study bias (e.g. publication bias) for any of the end-points of interest (Fig. 4).

\subsection{Frequency and consistency of stent thrombosis predictors}

Despite exploring a total of almost 50 candidate risk factors, no single predictor was proven universally successful at predicting stent thrombosis in all included studies, excluding those appraised in a small subset of studies and thus with limited external validity. Indeed, the most frequently and consistently reported predictors of cumulative definite/probable stent thrombosis were early antiplatelet therapy discontinuation, extent of coronary disease, and stent number/ length (Fig. 5; Table 4). Acute coronary syndrome at admission, diabetes, smoking status, and bifurcation/ostial disease also appeared as significant predictors, but less consistently.

Appraisal of the most powerful predictors, i.e. those with relative risk estimates $>5$ (Fig. 6), singled out antiplatelet therapy discontinuation before 30 days, residual dissection, antiplatelet therapy discontinuation between 30 days and 180 days, stent undersizing, prior brachytherapy, left ventricular systolic dysfunction, smoking status, bifurcational/ostial lesion, ACS at admission, and small vessel coronary disease. However, it must be emphasized that these are not pooled estimates but estimates from singles studies, and thus at high risk of small study effects and reporting bias. The complex clustering of predictors of definite, definite or probable, and definite, probable or possible stent thrombosis is summarized in Fig. 7.

As an exploratory analysis, we limited our analyses of predictors to large studies ( $>5000$ patients) at low risk of bias $[3,6,54$, $56,59,67,72,73,76]$. In this subsample of 9 studies, including a total of 153,350 patients and 2495 thromboses, the most common independent predictors of definite or probable stent thrombosis were diabetes (reported in 7 out of 9 studies), ACS at admission ( 5 out of 9 ),

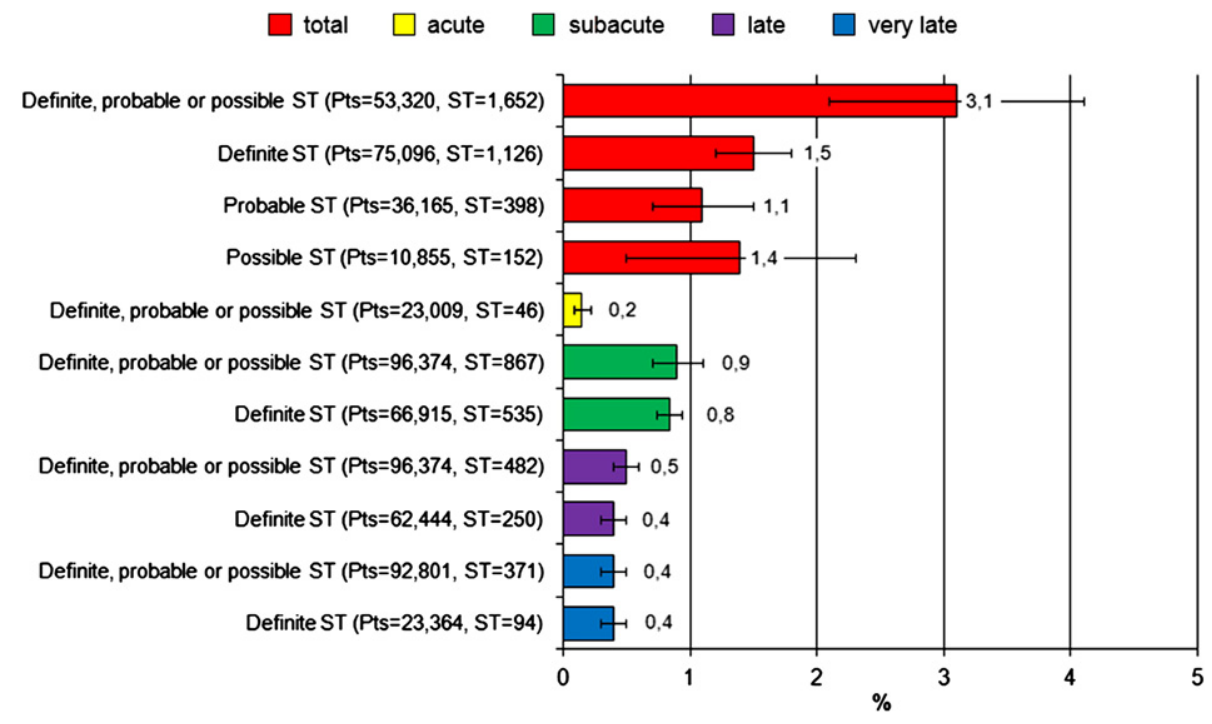

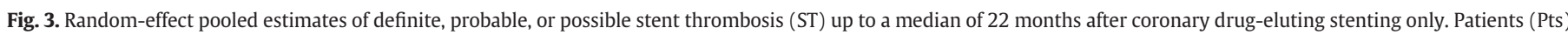
included and stent thromboses are reported in brackets. 


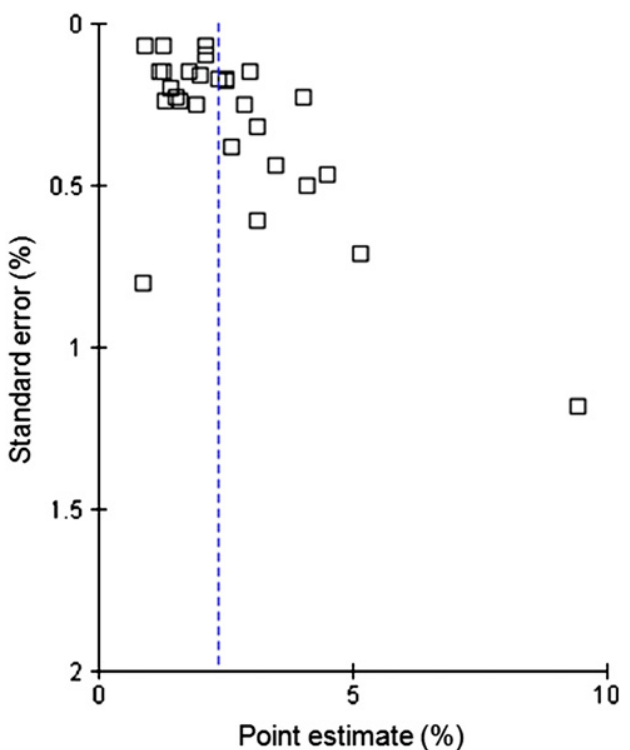

Fig. 4. Funnel plot for the cumulative rate of definite, probable or possible stent thrombosis.

total stent number/length (5 out of 9), antiplatelet therapy discontinuation before 30 days ( 3 out of 9 ), and extent of coronary disease (3 out of 9 ).

\section{Discussion}

To the best of our knowledge, this is the first and only collaborative systematic review focusing on incidence and predictors of stent thrombosis, aimed at informed clinical decision-making before coronary stenting (i.e. when bypass surgery or medical therapy could still be preferred), as well as long after stenting. The main findings of our work are four-fold: a) stent thrombosis occurs in up to $2.4 \%$ of patients up to 2 years stenting; b) given its ominous implications [1-11], even such an uncommon event remains a clinical priority; c) despite a plethora of candidate predictors, risk prognostication in the individual patient to tailor decision-making remains challenging, but should best be based on the few prevalent and consistent significant predictors hereby identified: early antiplatelet therapy discontinuation, extent of coronary disease, and stent number/length, as well as, but to a lesser extent, ACS at admission, diabetes, smoking status, and bifurcation/ostial disease; d) additional studies exploring other predictors (e.g. biomarkers) may prove worthwhile, but it is rather unlikely that any further powerful and common predictor can be identified capable of providing additional prognostic ability on top of the predictors singled out by this systematic review.

Thanks to its comprehensiveness, our study provides evidence applicable to various clinical scenarios and patients with different clinical and angiographic features. Indeed, assuming recent estimates hold true, the patient population included in our meta-analysis exceeds the number of patients undergoing $\mathrm{PCI}$ in any single large European country yearly. Moreover, in order to provide a real-world perspective on coronary stenting, we considered studies involving both BMS and DES [79]. Whereas some cardiologists have advocated in the past an almost universal adoption of DES, and despite their evident benefits on restenosis, BMS remain commonly used, especially in patients less likely to comply with a prolonged dual antiplatelet regime, and they should not be viewed as obsolete, in Europe as well as North America [80].

The present analysis was focused on time-related rates of stent thrombosis. Interestingly subacute and late stent thromboses were the most frequent events, especially for patients with DES implantation. Acute stent thrombosis, despite the same ominous impact on survival [7], is both the less frequently and the less thoroughly analyzed subtype of thrombosis [81-84]. Similar methodological hurdles have also limited so far the investigation of very late stent thrombosis $[85,86,87]$.

None of the 47 candidate predictors of stent thrombosis identified in the various studies occurred in all the studies included, reflecting the complex pathophysiology of stent thrombosis, limitations in its diagnosis and classification, its rare occurrence, and the ensuing challenges in conducting case-control or cohort studies capable of providing precise, accurate, and consistent statistical results. Nonetheless, early antiplatelet therapy discontinuation, extent of coronary disease, and stent number/length, were commonly and consistently identified as predictors of all subtypes of stent thrombosis.

In terms of strength of association, our work cannot provide clear scientific evidence in favor or against any predictor, as no formal meta-analytic pooling was performed focusing on predictors. However, extracting data from individual studies suggests that dual antiplatelet therapy discontinuation may be one of the most powerful predictors, especially if occurring before 30 days after PCI. The main drawback of such a statement is however the fact that only a minority of studies formally tested the independent prognostic role of this predictor. In addition, information bias (e.g. recall bias) may have played a role in overestimating the strength of this association. Residual dissection and stent undersizing were also impacting factors, yet

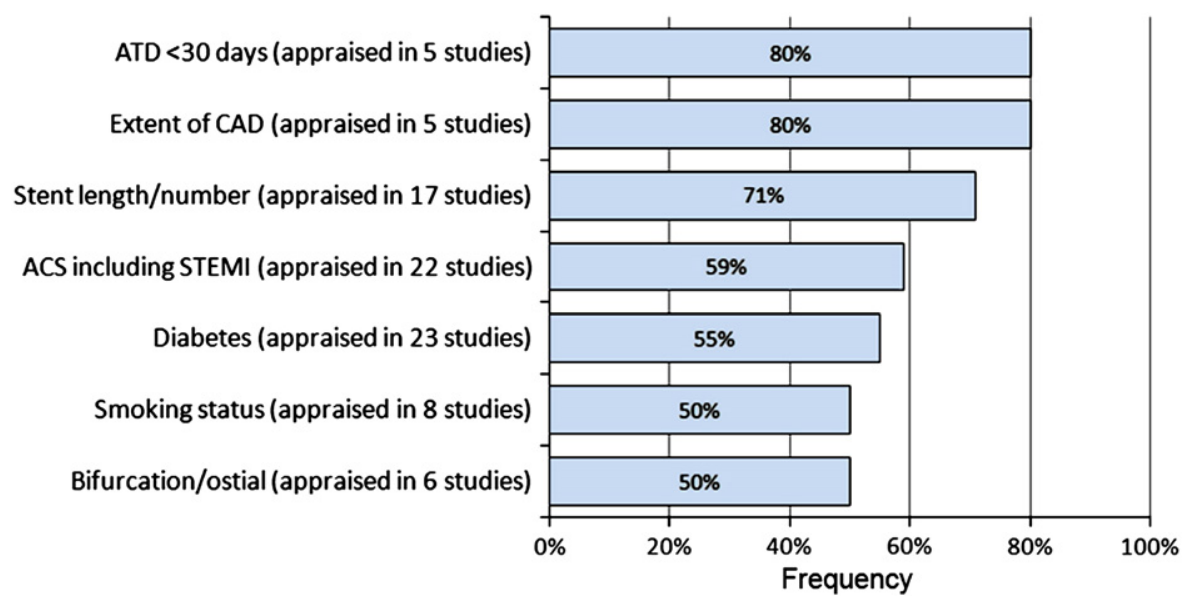

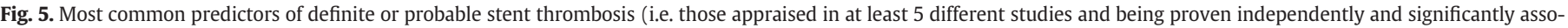

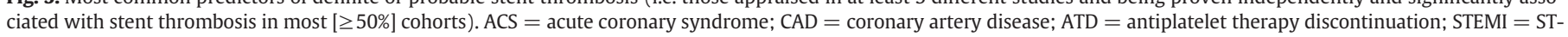
elevation myocardial infarction. 
Table 4

Most commonly reported predictors of stent thrombosis divided by subtype and ordered according to frequency of formal appraisal.

\begin{tabular}{|c|c|c|c|c|}
\hline Predictor & $\begin{array}{l}\text { Formal appraisal } \\
\text { (studies }=30 ; \\
\text { Pts }=221,066 \text { ) }\end{array}$ & $\begin{array}{l}\text { Any stent thrombosis } \\
\text { (studies }=30 ; \\
\text { Pts }=221,066 \text { ) }\end{array}$ & $\begin{array}{l}\text { Definite thrombosis } \\
\text { (studies =8; }[2,57,58,62,64,68, \\
\text { 72,73,75-77] Pts }=124,967 \text { ) }\end{array}$ & $\begin{array}{l}\text { Definite, or probable thrombosis } \\
\text { (studies =20; }[2,7,50,51,53,54,56-59 \text {, } \\
61-64,68,69,71-77] \text { Pts }=199,546 \text { ) }\end{array}$ \\
\hline Diabetes mellitus & 23 & 15 & 4 & 12 \\
\hline Acute coronary syndrome at admission & 22 & 15 & 8 & 13 \\
\hline Age & 22 & 4 & 0 & 4 \\
\hline Total stent number/stent length & 17 & 15 & 5 & 12 \\
\hline Hypertension & 17 & 1 & 0 & 1 \\
\hline Chronic renal failure & 10 & 6 & 1 & 4 \\
\hline Left ventricular systolic dysfunction & 10 & 5 & 1 & 3 \\
\hline Prior percutaneous coronary intervention & 10 & 3 & 1 & 3 \\
\hline Smoking status & 8 & 4 & 1 & 4 \\
\hline Chronic total occlusion & 7 & 2 & 1 & 2 \\
\hline Antiplatelet therapy discontinuation (30-180 days) & 7 & 3 & 1 & 1 \\
\hline Bifurcation/ostial lesion & 6 & 4 & 2 & 3 \\
\hline Restenosis treatment & 6 & 4 & 2 & 3 \\
\hline Small vessel coronary disease & 6 & 3 & 0 & 2 \\
\hline Antiplatelet therapy discontinuation ( $<30$ days) & 5 & 4 & 2 & 4 \\
\hline Extent of coronary artery disease & 5 & 3 & 1 & 4 \\
\hline Shock & 5 & 2 & 1 & 2 \\
\hline Calcified lesion & 5 & 3 & 0 & 2 \\
\hline Paclitaxel-eluting stent implantation & 4 & 3 & 2 & 3 \\
\hline Peripheral artery disease & 4 & 2 & 1 & 2 \\
\hline Vein graft stenting & 4 & 2 & 0 & 2 \\
\hline Left anterior descending stenting & 4 & 1 & 0 & 0 \\
\hline Drug-eluting stent implantation & 3 & 2 & 1 & 2 \\
\hline Post-procedural TIMI flow $<3$ & 3 & 2 & 1 & 2 \\
\hline Residual dissection & 3 & 2 & 1 & 2 \\
\hline Congestive heart failure & 3 & 2 & 0 & 2 \\
\hline Off-label drug-eluting stent use & 3 & 2 & 0 & 2 \\
\hline Cancer & 3 & 1 & 1 & 1 \\
\hline Left main disease & 3 & 0 & 1 & 1 \\
\hline Prior brachytherapy & 3 & 2 & 0 & 1 \\
\hline CYP2C19*2 genotype & 2 & 2 & 1 & 1 \\
\hline Stent undersizing & 2 & 1 & 1 & 1 \\
\hline Stroke & 2 & 1 & 1 & 1 \\
\hline Anemia & 2 & 1 & 0 & 1 \\
\hline Prior myocardial infarction & 2 & 1 & 0 & 1 \\
\hline Obesity & 2 & 2 & 0 & 0 \\
\hline Lesion type & 2 & 1 & 0 & 0 \\
\hline Low platelet count & 1 & 1 & 1 & 1 \\
\hline SYNTAX score & 1 & 1 & 1 & 1 \\
\hline Thrombotic diathesis & 1 & 1 & 1 & 1 \\
\hline Black race & 1 & 1 & 1 & 1 \\
\hline CYP2C9/A1075C $\left({ }^{*} 1 .{ }^{*} 3\right)$ genotype & 1 & 1 & 1 & 1 \\
\hline Post-dilatation & 1 & 1 & 0 & 1 \\
\hline Pre-procedural TIMI flow $<1$ & 1 & 1 & 0 & 1 \\
\hline Resistance to antiplatelet agents & 1 & 1 & 0 & 1 \\
\hline Self-expandable stent implantation & 1 & 1 & 0 & 1 \\
\hline Sirolimus-eluting stent implantation & 1 & 1 & 0 & 1 \\
\hline Clopidogrel therapy & 1 & 1 & 0 & 0 \\
\hline Glycoprotein IIb/IIIa inhibitors & 1 & 1 & 0 & 0 \\
\hline
\end{tabular}

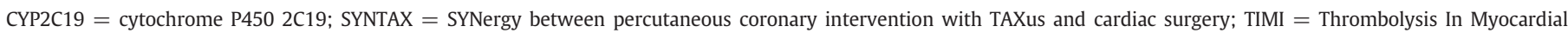
Infarction.

similarly uncommon [88]. Intriguingly, the physician aiming to exploit this information for risk stratification should bear in mind that some predictors may be very strong in terms of effect, but very rare (e.g. prior brachytherapy), whereas others might be less potent in statistical effect, but clinically much more meaningful given their common occurrence (e.g. diabetes).

These findings also support a complex and highly multifactorial model for the pathophysiology of stent thrombosis, without any single culprit factor, despite being ominous per se, being sufficient alone to cause stent thrombosis in a sizable portion of patients. In addition, none of the included studies systematically appraised the impact of other potentially relevant risk factors, which may play a hitherto unrecognized role in causing or contributing to stent thrombosis, such as strenuous exercise, stress, infections, intercurrent illness, and bleeding events.

Therefore, stent thrombosis cannot be systematically avoided just by addressing a single or a few risk factors, but only through a global appraisal and management of each individual patient. Two frequently challenging questions will also arise for physicians managing patients with stent who require non-cardiac surgery or those with atrial fibrillation. It has been recently demonstrated that subjects undergoing non-cardiac surgery are less likely to take aspirin and clopidogrel, and are at higher risk of thrombotic events [89]. Moreover, recent consensus statements on atrial fibrillation [90,91] have provided important yet controversial recommendations on stent implantation and antithrombotic therapy in these patients. To correctly manage these patients, it becomes fundamental to individually risk-stratify the patient before and after PCI in terms of both thrombotic and bleeding risk, and choose the most appropriate management strategy. Accordingly, an explicit choice between a more aggressive antiplatelet therapy with prasugrel, ticagrelor or glycoprotein IIb/IIIa inhibitors, or a less invasive strategy with implantation of BMS could be envisioned [15]. Important insights will be provided also by studies focusing on high residual platelet reactivity as a marker of the risk of stent 


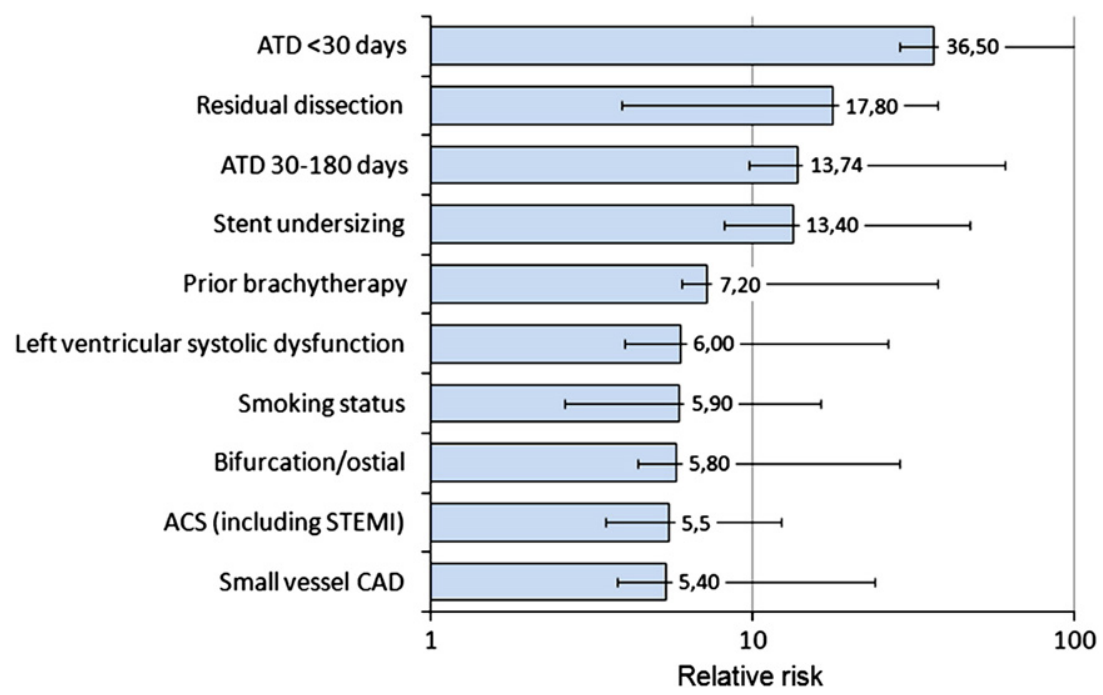

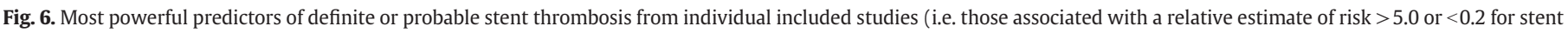
thrombosis). ACS = acute coronary syndrome; ATD = antiplatelet therapy discontinuation; CAD = coronary artery disease; STEMI $=$ ST-elevation myocardial infarction.

thrombosis [45]. This holds even truer for patients who have already experienced a stent thrombosis and in whom medical therapy must be aptly chosen and maximized to avoid recurrences. Indeed, we appraised formally the association between stent thrombosis and resistance to antiplatelet agents and found that specific genotypes associated with resistance to antiplatelet agents and resistance to antiplatelet agents itself as measured by platelet function assay was associated with stent thrombosis in a subset of studies. Whether this apparently limited association after multivariable adjustment between resistance to antiplatelet agents and stent thrombosis is due to selective reporting or publication bias requires additional research [92].

Notably, age, lesion subtype, renal failure, diabetes mellitus, and ejection fraction, as well as many others, are all very important predictive factors and would require detailed analyses. Indeed, we reported that they all were, albeit with variable consistency, associated with stent thrombosis, thus confirming even in our work their important prognostic impact. However, additional analyses were

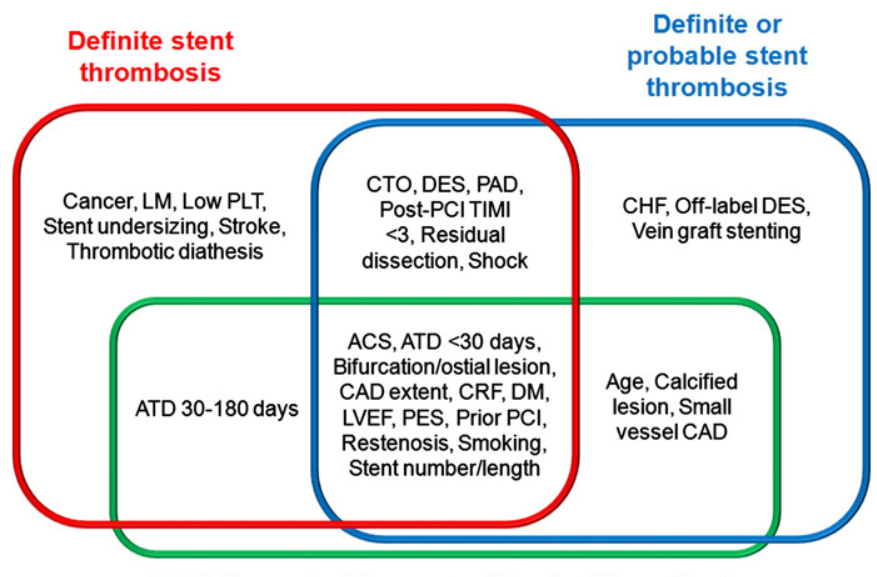

Definite, probable or possible stent thrombosis

Fig. 7. Venn diagram synthesizing the most common predictors of stent thrombosis (i.e. those present in at least $10 \%$ of included studies), according to Academic Research Consortium definitions. ATD = antiplatelet therapy discontinuation; CAD = coronary artery disease; $\mathrm{CHF}=$ congestive heart failure; $\mathrm{CRF}=$ chronic renal failure; $\mathrm{CTO}=$ chronic total occlusion; DES = drug-eluting stent; $\mathrm{DM}=$ diabetes mellitus; $\mathrm{LVEF}=$ left ventricular ejection fraction; PES = paclitaxel-eluting stent; PLT = platelets; LM = left main disease; $\mathrm{PAD}=$ peripheral artery disease; $\mathrm{PCI}=$ percutaneous coronary intervention; TIMI $=$ Thrombolysis In Myocardial Infarction flow. beyond the scope of our work. Indeed, definitions of these variables were different among the included studies, thus limiting the room for a careful and detailed analysis. In addition, a spectrum of severity can be envisioned for any of these variables, with important prognostic implications. For instance, we typically dichotomize bifurcation lesions as being present or absent. However, true bifurcations have a larger prognostic impact of pseudobifurcations, and the same applies to proximal bifurcations versus distal bifurcations, and to trifurcations compared to bifurcations with only one side branch [93]. The same applies to age, diabetes mellitus, renal failure, and systolic dysfunction, as well as to many other variables, which are often dichotomized, but more realistically present with a very large spectrum of values.

It has also been reported that statins, post-dilation and stent length can impact on both early and late events. Indeed, by study design, we were theoretically able to capture and appraise the prognostic role of any of these factors, as long as they were consistently reported in short-listed studies. We did confirm the association between stent length and stent thrombosis, and, to a lesser extent, the association between post-dilation and stent thrombosis. However, we did not find consistent data in support of the protective role of statins for stent thrombosis. However, as for stent type, our review was not adequately powered to establish the protective role of drug therapy, which is best tested by randomized clinical trials.

Finally, biomarkers in general and natriuretic peptides in particular have been proposed as potential predictors of stent thrombosis. We found however limited data in support of the prognostic role of any biomarker as far as stent thrombosis is concerned. However, there is evidence, albeit limited, that C-reactive protein can predict stent thrombosis [94]. Conversely, no study so far has suggested an association between natriuretic peptides and stent thrombosis. However, this by no means invalidates the pivotal prognostic role of natriuretic peptides across the spectrum of cardiovascular conditions.

\subsection{Limitations}

This work has several major drawbacks [95]. First, we focused on a rare event, fraught with the risk of selective reporting, and thus excluded 15 studies enrolling between 1000 and 1999 patients, which would have provided potentially biased estimates at multivariable analysis [21]. Second, we did not perform a pooled analysis of risk predictors, because this would have been limited by substantial reporting bias. Third, we focused on predictors of cumulative stent thrombosis but did not explore in details predictors of thrombosis 
at different times. Fourth, we included studies with a mixture of DES and BMS, often chosen at the discretion of the operator, with stent choice being most likely driven by several and complex confounders. Thus, the finding that DES did not prove consistently a predictor of stent thrombosis, should be viewed with caution, even if it appears in agreement with prior observational, randomized and metaanalytic studies. Peri-procedural events, including iatrogenic complications (e.g. plaque prolapse, plaque embolization, snow plough effect and dissection) [88], and ensuing increases in cardiac biomarkers [96] have very important implications in general and in causing subsequent stent thrombosis. However, focusing on such events in detail, as well as on ECG data, was beyond the scope of our work. Moreover, publication bias remains always a concern because the present review was based solely on published studies, yet small study bias was not apparent at funnel plot inspection. Most predictors were appraised in only a subset of studies, limiting the precise quantitative estimation of their independent predictive role. Another limitation, most likely the greatest one, of this review is the study-level setting, thus lacking the precision and flexibility of a patient-level work, which would have enabled more detailed analyses trying to disentangle the complex interplay between confounding factors, predictors, and events. Indeed, individual patient data would have provided more detailed information on incidence and predictors, but most likely would have required exclusion of several datasets, thus limiting unduly the external validity of the analyses [97]. Moreover, patient-level and study-level meta-analyses are often in agreement [98], and thus our findings should be consistent with future patientlevel works on this topic. In addition, diagnostic criteria and definitions of stent thrombosis have changed over time, and these changes may have introduced the risk of information bias. Finally, we aimed to provide a comprehensive synthesis of potentially useful clinical predictors of stent thrombosis, to guide invasive and non-invasive cardiologists in their everyday risk-prognostication effort, but not challenge predictors with established role in this setting such as duration of dual antiplatelet therapy and stent type $[51,69]$. Only existing or future randomized trials of such medical interventions can inform on their risk-benefit balance in preventing stent thrombosis.

\section{Conclusions}

Despite numerous possible risk factors, the most common and consistent predictors of stent thrombosis are early antiplatelet therapy discontinuation, extent of coronary disease, and stent number/ length. Knowledge of these risk factors is essential to inform appropriate clinical decision making when considering the risks versus benefits or coronary stents.

Supplementary materials related to this article can be found online at doi:10.1016/j.ijcard.2012.01.080.

\section{Funding}

None.

\section{Conflict of interest}

Dr. Biondi-Zoccai has received research support from Eli Lilly, has consulted for Abbott Vascular, Cordis and Medtronic, has lectured for AstraZeneca, Boston Scientific, Bristol Myers Squibb, Chiesi, Medtronic, Sanofi Aventis and The Medicine Company, and has received career grant support from Medtronic.

Dr. Stone has served as a member of the scientific advisory board and has received honoraria from Abbott Vascular and Boston Scientific, and has consulted for AstraZeneca, Bristol Myers Squibb, Eli Lilly, and Merck.

Dr. Urban has consulted for Biosensors and Cordis and has lectured for Medtronic and Terumo.
Dr. Jensen consulted for Abbott Vascular and Cordis.

Dr. Applegate has served as a member for, has received research support from, and has received honoraria from Abbott Vascular and St Jude Medical. Dr. Biondi-Zoccai has received research support from Eli Lilly, has consulted for Abbott Vascular, Cordis and Medtronic, has lectured for AstraZeneca, Boston Scientific, Bristol Myers Squibb, Chiesi, Medtronic, Sanofi Aventis and The Medicine Company, and has received career grant support from Medtronic. Dr. Stone has served as a member of the scientific advisory board and has received honoraria from Abbott Vascular and Boston Scientific, and has consulted for AstraZeneca, Bristol Myers Squibb, Eli Lilly, Medtronic, and Merck. Dr. Urban has consulted for Biosensors and Cordis and has lectured for Medtronic and Terumo. Dr. Okkel Jensen consulted for Abbott Vascular and Cordis.

\section{Acknowledgments}

Concerning authors' contributions, Dr. Biondi-Zoccai conceived the review, participated in data collection, analysis, and manuscript drafting, had full access to all the data in the study and takes responsibility for the integrity of the data and the accuracy of the data analysis.

Dr. D'Ascenzo collected data, performed the analyzed and codrafted the manuscript.

Drs. Bollati, Clementi, Castagno, Lagerqvist, de la Torre Hernandez, ten Berg, Brodie, Urban, Okkels Jensen, Sardi, Waksman, Lasala, Schulz, Stone, Airoldi, Colombo, Lemesle, Applegate, Buonamici, Kirtane, Undas, Sheiban, Gaita, Sangiorgi, Modena, and Frati participated in acquisition of data, analysis, interpretation, and manuscript drafting, revising it critically for key intellectual content. We also thank Claudia Nibaldini for her outstanding support. Finally, the authors of this manuscript have certified that they comply with the Principles of Ethical Publishing in the International Journal of Cardiology.

\section{References}

[1] Holmes Jr DR, Kereiakes DJ, Garg S, et al. Stent thrombosis. J Am Coll Cardiol 2010;56:1357-65.

[2] Daemen J, Wenaweser P, Tsuchida K, et al. Early and late coronary stent thrombosis of sirolimus-eluting and paclitaxel-eluting stents in routine clinical practice: data from a large two-institutional cohort study. Lancet 2007;369:667-78.

[3] de la Torre-Hernández JM, Alfonso F, Hernández F, et al. Drug-eluting stent thrombosis: results from the multicenter Spanish registry ESTROFA (Estudio ESpañol sobre TROmbosis de stents FArmacoactivos). J Am Coll Cardiol 2008;51: 986-90.

[4] Lemesle G, De Labriolle A, Bonello L, et al. Clinical manifestation and prognosis of early versus late stent thrombosis of drug-eluting stents. J Interv Cardiol 2009;22: 228-33.

[5] Chechi T, Vecchio S, Vittori G, et al. ST-segment elevation myocardial infarction due to early and late stent thrombosis a new group of high-risk patients. J Am Coll Cardiol 2008;51:2396-402.

[6] Ergelen M, Gorgulu S, Uyarel H, et al. The outcome of primary percutaneous coronary intervention for stent thrombosis causing ST-elevation myocardial infarction. Am Heart J 2010;159:672-6.

[7] Lasala JM, Cox DA, Dobies D, et al. Drug-eluting stent thrombosis in routine clinical practice: two-year outcomes and predictors from the TAXUS ARRIVE registries. Circ Cardiovasc Interv 2009;2:285-93.

[8] Cutlip DE, Baim DS, Ho KK, et al. Stent thrombosis in the modern era: a pooled analysis of multicenter coronary stent clinical trials. Circulation 2001;103: 1967-71.

[9] Kuchulakanti PK, Chu WW, Torguson R, et al. Correlates and long-term outcomes of angiographically proven stent thrombosis with sirolimus- and paclitaxeleluting stents. Circulation 2006;113:1108-13.

[10] Lemesle G, Sudre A, Modine T, et al. High incidence of recurrent in stent thrombosis after successful treatment of a first in stent thrombosis. Catheter Cardiovasc Interv 2008;72:470-8.

[11] Wenaweser P, Rey C, Eberli FR, et al. Stent thrombosis following bare-metal stent implantation: success of emergency percutaneous coronary intervention and predictors of adverse outcome. Eur Heart J 2005;26:1180-7.

[12] Farb A, Boam AB. Stent thrombosis redux-the FDA perspective. N Engl J Med 2007;356:984-7.

[13] King 3 rd SB, Smith Jr SC, Hirshfeld Jr JW, et al. 2007 Focused Update of the ACC/AHA SCAI 2005 Guideline Update for Percutaneous Coronary Intervention: a report of the American College of Cardiology/American Heart Association Task Force on Practice Guidelines. Circulation 2008;117:261-95.

[14] Roe MT, Chen AY, Cannon CP, et al. Temporal changes in the use of drug-eluting stents for patients with non-ST-segment elevation myocardial infarction 
undergoing percutaneous coronary intervention from 2006 to 2008. Results from the CRUSADE and ACTION-GWTG registries. Circ Cardiovasc Qual Outcomes 2009;2:414-20.

[15] Biondi-Zoccai G, Lotrionte M, Agostoni P, et al. Adjusted indirect comparison meta-analysis of prasugrel versus ticagrelor for patients with acute coronary syndromes. Int J Cardiol 2011;150:325-31.

[16] Moher D, Cook DJ, Eastwood S, Olkin I, Rennie D, Stroup DF. Improving the quality of reports of meta-analyses of randomised controlled trials: the QUOROM statement. Quality of Reporting of Meta-analyses. Lancet 1999;354:1896-900.

[17] Liberati A, Altman DG, Tetzlaff J, et al. The PRISMA statement for reporting systematic reviews and meta-analyses of studies that evaluate healthcare interventions: explanation and elaboration. BMJ 2009;339:b2700.

[18] Stroup DF, Berlin JA, Morton SC, et al. Meta-analysis of observational studies in epidemiology: a proposal for reporting. Meta-analysis Of Observational Studies in Epidemiology (MOOSE) group. JAMA 2000;283:2008-12.

[19] Higgins JPT, Green S, editors. Cochrane Handbook for Systematic Reviews of Interventions Version 5.0.2 [updated September 2009]. The Cochrane Collaboration; 2009. Available from www.cochrane-handbook.org. (last accessed on February 11, 2011).

[20] Wilczynski NL, Haynes RB; for the Hedges Team. Developing optimal search strategies for detecting clinically sound prognostic studies in MEDLINE: an analytic survey. BMC Med 2004;2:23.

[21] Biondi-Zoccai G, Romagnoli E, Agostoni P, et al. Are propensity scores really superior to standard multivariable analysis? Contemp Clin Trials 2011;32:731-40.

22] Cutlip DE, Windecker S, Mehran R, et al. Academic Research Consortium. Clinica end points in coronary stent trials: a case for standardized definitions. Circulation 2007;115:2344-51.

[23] Ross JS, Mulvey GK, Stauffer B, et al. Statistical models and patient predictors of readmission for heart failure: a systematic review. Arch Intern Med 2008;168: 1371-86.

[24] Szük T, Gyöngyösi M, Homorodi N, et al. Effect of timing of clopidogrel administration on 30-day clinical outcomes: 300-mg loading dose immediately after coronary stenting versus pretreatment 6 to 24 hours before stenting in a large unselected patient cohort. Am Heart J 2007;153:289-95.

[25] Kimura T, Morimoto T, Kozuma K, et al. Comparisons of baseline demographics, clinical presentation, and long-term outcome among patients with early, late, and very late stent thrombosis of sirolimus-eluting stents: Observations from the Registry of Stent Thrombosis for Review and Reevaluation (RESTART). Circulation 2010;122:52-61.

[26] Akin I, Bufe A, Schneider S, et al. Clinical outcomes in diabetic and non-diabetic patients with drug-eluting stents: results from the first phase of the prospective multicenter German DES.DE registry. Clin Res Cardiol 2010;99:393-400.

[27] Rabinovitz A, Bier DM, Wagman GM, et al. Association between off-label use of drug-eluting stents and subsequent stent thrombosis: a case-control analysis. J Invasive Cardiol 2010;22:15-9.

[28] Jain AK, Lotan C, Meredith IT, et al. Twelve-month outcomes in patients with diabetes implanted with a zotarolimus-eluting stent: results from the E-Five Registry. Heart 2010;96:848-53.

[29] Applegate RJ, Sacrinty MT, Little WC, Santos RM, Gandhi SK, Kutcher MA. Incidence of coronary stent thrombosis based on academic research consortium definitions. Am J Cardiol 2008;102:683-8.

[30] Lotan C, Meredith IT, Mauri L, Liu M, Rothman MT; E-Five Investigators. Safety and effectiveness of the Endeavor zotarolimus-eluting stent in real-world clinical practice: 12-month data from the E-Five registry. JACC Cardiovasc Interv 2009;2:1227-35

[31] Wenaweser P, Rey C, Eberli FR, et al. Stent thrombosis following bare-metal stent implantation: success of emergency percutaneous coronary intervention and predictors of adverse outcome. Eur Heart J 2005;26:1180-7.

[32] Huczek Z, Filipiak KJ, Kochman J, et al. Baseline platelet size is increased in patients with acute coronary syndromes developing early stent thrombosis and predicts future residual platelet reactivity. A case-control study. Thromb Res 2010;125:406-12.

[33] Chen JL, Gao LJ, Yang YJ, et al. Comparison of the incidence of late stent thrombosis after implantation of different drug-eluting stents in the real world coronary heart disease patients: three-year follow-up results. Chin Med J (Engl) 2010;123: 778-81.

[34] Le Feuvre C, Helft G, Cohen S, et al. Characteristics and prognosis of patients with angiographic stent thrombosis: comparison between drug-eluting and baremetal stents. Arch Cardiovasc Dis 2008;101:220-5.

[35] Doyle B, Rihal CS, O'Sullivan CJ, et al. Outcomes of stent thrombosis and restenosis during extended follow-up of patients treated with bare-metal coronary stents. Circulation 2007;116:2391-8.

[36] Win HK, Caldera AE, Maresh K, et al. EVENT Registry Investigators. Clinical outcomes and stent thrombosis following off-label use of drug-eluting stents. JAMA 2007;297:2001-9.

[37] Suh JW, Baek SH, Park JS, et al. Vitamin K epoxide reductase complex subunit 1 gene polymorphism is associated with atherothrombotic complication after drug-eluting stent implantation: 2-Center prospective cohort study. Am Heart J 2009;157:908-12

[38] Daemen J, van Twisk PH, Kukreja N, et al. The relative safety and efficacy of baremetal and drug-eluting stents in low and high-risk patient subsets. An epidemiological analysis of three sequential cohorts of consecutive all comers $(n=6129)$. EuroIntervention 2009;4:464-74.

[39] Kaltoft A, Jensen LO, Maeng M, et al. 2-year clinical outcomes after implantation of sirolimus-eluting, paclitaxel-eluting, and bare-metal coronary stents: results from the WDHR (Western Denmark Heart Registry). J Am Coll Cardiol 2009;53. 658-64.
[40] Kukreja N, Onuma Y, Garcia-Garcia HM, et al. The risk of stent thrombosis in patients with acute coronary syndromes treated with bare-metal and drug-eluting stents. JACC Cardiovasc Interv 2009;2:534-41.

[41] Park DW, Flaherty JD, Davidson CJ, et al. Prognostic influence of diabetes mellitus on long-term clinical outcomes and stent thrombosis after drug-eluting stent implantation in asian patients. Am J Cardiol 2009;103:646-52.

[42] Roy P, Bonello L, Torguson R, et al. Temporal relation between clopidogrel cessation and stent thrombosis after drug-eluting stent implantation. Am J Cardiol 2009; 103:801-5.

[43] Jensen LO, Maeng M, Thayssen P, et al. Clinical outcome after primary percutaneous coronary intervention with drug-eluting and bare metal stents in patients with ST-segment elevation myocardial infarction. Circ Cardiovasc Interv 2008;1: 176-84.

[44] Giusti B, Gori AM, Marcucci R, et al. Relation of cytochrome P450 2 C19 loss-offunction polymorphism to occurrence of drug-eluting coronary stent thrombosis. Am J Cardiol 2009;103:806-11.

[45] Gori AM, Marcucci R, Migliorini A, et al. Incidence and clinical impact of dual nonresponsiveness to aspirin and clopidogrel in patients with drug-eluting stents. J Am Coll Cardiol 2008;52:734-9.

[46] Iakovou I, Schmidt T, Bonizzoni E, et al. Incidence, predictors, and outcome of thrombosis after successful implantation of drug-eluting stents. JAMA 2005;293: 2126-30.

[47] Baran KW, Lasala JM, Cox DA, et al. A clinical risk score for prediction of stent thrombosis. Am J Cardiol 2008;102:541-5.

[48] Harmsze AM, van Werkum JW, Ten Berg JM, et al. CYP2C19*2 and CYP2C9*3 alleles are associated with stent thrombosis: a case-control study. Eur Heart J 2010;31:3046-53.

[49] Parodi G, Memisha G, Bellandi B, et al. Effectiveness of primary percutaneous coronary interventions for stent thrombosis. Am J Cardiol 2009;103:913-6.

[50] Song GY, Yang YJ, Xu B, et al. ST-elevated acute myocardial infarction happening 1 month post stent implantation: late thrombosis in-stents or new lesions? Chin Med J (Engl) 2009;122:1610-4.

[51] Becker D, Maurovich-Horvat P, Barczi G, et al. Life after coronary stent thrombosis. Med Sci Monit 2009;15:CR236-41.

[52] Del Pace S, Boddi M, Rasoini R, et al. Acute infection-inflammation and coronary stent thrombosis: an observational study. Intern Emerg Med 2010;5:121-6.

[53] Airoldi F, Colombo A, Morici N, et al. Incidence and predictors of drug-eluting stent thrombosis during and after discontinuation of thienopyridine treatment. Circulation 2007;116:745-54.

[54] Aoki J, Lansky AJ, Mehran R, et al. Early stent thrombosis in patients with acute coronary syndromes treated with drug-eluting and bare metal stents: the Acute Catheterization and Urgent Intervention Triage Strategy trial. Circulation 2009;119:687-98.

[55] Applegate RJ, Sacrinty MT, Kutcher MA, Santos RM, Gandhi SK, Little WC. 3-year comparison of drug-eluting versus bare-metal stents. JACC Cardiovasc Interv 2009;2:231-9.

[56] Brodie BR, Stuckey T, Downey W, et al. Outcomes and complications with off-label use of drug-eluting stents: results from the STENT (Strategic Transcatheter Evaluation of New Therapies) group. JACC Cardiovasc Interv 2008;1:405-14.

[57] Buonamici P, Marcucci R, Migliorini A, et al. Impact of platelet reactivity after clopidogrel administration on drug-eluting stent thrombosis. J Am Coll Cardiol 2007;49:2312-7.

[58] Park DW, Yun SC, Lee SW, et al. Stent thrombosis, clinical events, and influence of prolonged clopidogrel use after placement of drug-eluting stent data from an observational cohort study of drug-eluting versus bare-metal stents. JACC Cardiovasc Interv 2008;1:494-503.

[59] Ergelen M, Uyarel H, Osmonov D, et al. Early stent thrombosis in patients undergoing primary coronary stenting for acute myocardial infarction: incidence, a simple risk score, and prognosis. Clin Appl Thromb Hemost 2010;16:33-41.

[60] Hoffmann R, Klinker H, Adamu U, Kelm M, Blindt R. The risk of definitive stent thrombosis is increased after "off-label" stent implantation irrespective of drugeluting stent or bare-metal stent use. Clin Res Cardiol 2009;98:549-54.

[61] Lagerqvist B, Carlsson J, Fröbert O, et al. Stent thrombosis in Sweden: a report from the Swedish Coronary Angiography and Angioplasty Registry. Circ Cardiovasc Interv 2009;2:401-8.

[62] Lemesle G, Delhaye C, Sudre A, et al. Impact of high loading and maintenance dose of clopidogrel within the first 15 days after percutaneous coronary intervention on patient outcome. Am Heart J 2009;157:375-82.

[63] Machecourt J, Danchin N, Lablanche JM, et al. Risk factors for stent thrombosis after implantation of sirolimus-eluting stents in diabetic and nondiabetic patients: the EVASTENT Matched-Cohort Registry. J Am Coll Cardiol 2007;50:501-8.

[64] Mishkel GJ, Moore AL, Markwell S, Shelton ME. Correlates of late and very late thrombosis of drug eluting stents. Am Heart J 2008;156:141-7.

[65] Jensen LO, Tilsted HH, Thayssen P, et al. Paclitaxel and sirolimus eluting stents versus bare metal stents: long-term risk of stent thrombosis and other outcomes. From the Western Denmark Heart Registry. EuroIntervention 2010;5:898-905.

[66] Pinto Slottow TL, Steinberg DH, Roy PK, et al. Observations and outcomes of definite and probable drug-eluting stent thrombosis seen at a single hospital in a four-year period. Am J Cardiol 2008;102:298-303.

[67] Rinaldi MJ, Kirtane AJ, Piana RN, et al. Clinical, procedural, and pharmacologic correlates of acute and subacute stent thrombosis: results of a multicenter casecontrol study with 145 thrombosis events. Am Heart J 2008;155:654-60.

[68] Sarno G, Garg S, Onuma Y, et al. The impact of body mass index on the one year outcomes of patients treated by percutaneous coronary intervention with Biolimus- and Sirolimus-eluting stents (from the LEADERS Trial). Am J Cardiol 2010;105:475-9. 
[69] Schulz S, Schuster T, Mehilli J, et al. Stent thrombosis after drug-eluting stent implantation: incidence, timing, and relation to discontinuation of clopidogrel therapy over a 4-year period. Eur Heart J 2009;30:2714-21.

[70] Serruys PW, Onuma Y, Garg S, et al. 5-year clinical outcomes of the ARTS Il (Arterial Revascularization Therapies Study II) of the sirolimus-eluting stent in the treatment of patients with multivessel de novo coronary artery lesions. J Am Coll Cardiol 2010;55:1093-101.

[71] Smit JJ, van't Hof AW, de Boer MJ, et al. Incidence and predictors of subacute thrombosis in patients undergoing primary angioplasty for an acute myocardial infarction. Thromb Haemost 2006;96:190-5.

[72] Tolleson TR, Newby LK, Harrington RA, et al. Frequency of stent thrombosis after acute coronary syndromes (from the SYMPHONY and 2nd SYMPHONY trials). Am J Cardiol 2003;92:330-3.

[73] Undas A, Zalewski J, Krochin M, et al. Altered plasma fibrin clot properties are associated with in-stent thrombosis. Arterioscler Thromb Vasc Biol 2010;30: 276-82.

[74] Urban P, Gershlick AH, Guagliumi G, et al. Safety of coronary sirolimus-eluting stents in daily clinical practice: one-year follow-up of the e-Cypher registry. Circulation 2006;113:1434-41.

[75] van Werkum JW, Heestermans AA, Zomer AC, et al. Predictors of coronary stent thrombosis: the Dutch Stent Thrombosis Registry. J Am Coll Cardiol 2009;53: 1399-409.

[76] Waksman R, Buch AN, Torguson R, et al. Long-term clinical outcomes and thrombosis rates of sirolimus-eluting versus paclitaxel-eluting stents in an unselected population with coronary artery disease (REWARDS registry). Am J Cardiol 2007; 100:45-51.

[77] Wang ZJ, Zhou YJ, Liu YY, et al. Obesity and cardiovascular thrombotic events in patients undergoing percutaneous coronary intervention with drug-eluting stents. Heart 2009;95:1587-92.

[78] Wenaweser P, Daemen J, Zwahlen M, et al. Incidence and correlates of drugeluting stent thrombosis in routine clinical practice. 4-year results from a large 2-institutional cohort study. J Am Coll Cardiol 2008;52:1134-40.

[79] Yan BP, Duffy SJ, Clark DJ, et al. Rates of stent thrombosis in bare-metal versus drug-eluting stents (from a large Australian multicenter registry). Am J Cardiol 2008; 101:1716-22.

[80] Collins SD, Torguson R, Gaglia Jr MA, et al. Does black ethnicity influence the development of stent thrombosis in the drug-eluting stent era? Circulation 2010;122:1085-90.

[81] Agostoni P, Kedhi E, Verheye S, Vermeersch P, Van Langenhove G. Dissimilar relevance given to diseases by medical literature, and the potential to create biases in the clinical decision-making process: the case of late stent thrombosis. Int J Cardiol 2007;114:E38-9.

[82] Venkitachalam L, Lei Y, Stolker JM, et al. Clinical and economic outcomes of liberal versus selective drug-eluting stent use: insights from temporal analysis of the multicenter evaluation of drug eluting stents and ischemic events (EVENT) registry. Circulation 2011;124:1028-37.

[83] Biondi-Zoccai GG, Sangiorgi GM, Chieffo A, et al. Validation of predictors of intraprocedural stent thrombosis in the drug-eluting stent era. Am J Cardiol 2005;95: 1466-8.
[84] Alfonso F, Suárez A, Angiolillo DJ, et al. Findings of intravascular ultrasound during acute stent thrombosis. Heart 2004;90:1455-9.

[85] Sangiorgi GM, Clementi F, Cola C, Biondi-Zoccai G. Plaque vulnerability and related coronary event prediction by intravascular ultrasound with virtual histology: "it's a long way to tipperary"? Catheter Cardiovasc Interv 2007;70:203-10.

[86] Hou J, Qi H, Zhang M, et al. Development of lipid-rich plaque inside bare metal stent: possible mechanism of late stent thrombosis? An optical coherence tomography study. Heart 2010;96:1187-90.

[87] Agostoni P, Vermeersch P, Knaapen M, Verheye S. Stent thrombosis is not always stent thrombosis: de novo atherosclerosis in a stented coronary segment. Int J Cardiol 2010;144:E19-21.

[88] Biondi-Zoccai GG, Agostoni P, Sangiorgi GM, et al. Incidence, predictors, and outcomes of coronary dissections left untreated after drug-eluting stent implantation. Eur Heart J 2006;27:540-6.

[89] Berger PB, Kleiman NS, Pencina MJ, et al. Frequency of major noncardiac surgery and subsequent adverse events in the year after drug-eluting stent placement results from the EVENT (Evaluation of Drug-Eluting Stents and Ischemic Events) Registry. JACC Cardiovasc Interv 2010;3:920-7.

[90] Lip GY, Huber K, Andreotti F, et al. Management of antithrombotic therapy in atrial fibrillation patients presenting with acute coronary syndrome and/or undergoing percutaneous coronary intervention/stenting. Thromb Haemost 2010;103:13-28.

[91] European Heart Rhythm Association, European Association for Cardio-Thoracic Surgery, Camm AJ, et al. Guidelines for the management of atrial fibrillation: the Task Force for the Management of Atrial Fibrillation of the European Society of Cardiology (ESC). Eur Heart J 2010;31:2369-429.

[92] Bauer T, Bouman HJ, van Werkum JW, Ford NF, ten Berg JM, Taubert D. Impact of CYP2C19 variant genotypes on clinical efficacy of antiplatelet treatment with clopidogrel: systematic review and meta-analysis. BMJ 2011;343:d4588.

[93] Sheiban I, Gerasimou A, Bollati M, et al. Early and long-term results of percutaneous coronary intervention for unprotected left main trifurcation disease. Catheter Cardiovasc Interv 2009;73:25-31.

[94] Park DW, Lee SW, Yun SC, et al. A point-of-care platelet function assay and Creactive protein for prediction of major cardiovascular events after drug-eluting stent implantation. J Am Coll Cardiol 2011;58:2630-9.

[95] Biondi-Zoccai GG, Agostoni P, Moretti C, Meliga E, Sheiban I Making sense of the recent meta-analytical confusion concerning the safety of drug-eluting stents. EuroIntervention 2007;3:381-5.

[96] Testa L, Van Gaal WJ, Biondi Zoccai GG, et al. Myocardial infarction after percutaneous coronary intervention: a meta-analysis of troponin elevation applying the new universal definition. QJM 2009;102:369-78.

[97] Ahmed I, Sutton AJ, Riley RD. Assessment of publication bias, selection bias, and unavailable data in meta-analyses using individual participant data: a database survey. BMJ 2012;344:d7762.

[98] Olkin I, Sampson A. Comparison of meta-analysis versus analysis of variance of individual patient data. Biometrics 1998 Mar;54:317-22. 